\title{
Antibodies to the C Epitope of Neisseria gonorrhoeae Are Present in Patients with Gonorrhoea and Absent in Normal Sera
}

\author{
By RAQUEL DEMARCO DE HORMAECHE, * HELEN JESSOP \\ AND CHRISTINE BUNDELL \\ Department of Pathology, University of Cambridge, Tennis Court Road, \\ Cambridge CB2 IQP, UK
}

(Received 9 September 1987; revised 3 December 1987)

\begin{abstract}
We have previously described a surface oligosaccharide antigen (epitope C) present in fresh isolates of Neisseria gonorrhoeae and in variants grown in subcutaneous chambers, but poorly formed by variants repeatedly subcultured in vitro. We have now investigated the presence of antibodies to epitope $C$ in sera from normal individuals and from patients with gonorrhoea. Sera were analysed by Western blotting and ELISA, and compared with a pool of sera from normal individuals with no known history of gonorrhoea. Antigenic extracts and monoclonal antibody to the $\mathrm{C}$ epitope were used for competition and inhibition studies. Only the sera from patients contained antibodies to epitope C. Antibodies to several other gonococcal antigens were found in sera from patients, and also in normal sera. Collectively, the results indicate that epitope $\mathrm{C}$ is expressed in humans, that patients with gonorrhoea develop antibodies to it, and that such antibodies are absent in sera of normal individuals.
\end{abstract}

\section{INTRODUCTION}

Soon after the onset of symptoms, patients with gonorrhoea mount an immune response to gonococcal antigens. Circulating and local antibodies have been found in patients of both sexes (Hess et al., 1965; Cohen, 1967; Cohen et al., 1969; Kearns et al., 1973a, b; O'Reilly et al., 1976; McMillan et al., 1979a, b, $c$; Kwapinski et al., 1978; Brooks \& Ingwer, 1979; Zak et al., 1984; Lammel et al., 1985), and a cell-mediated immune response has been demonstrated after single or repeated infections (Kearns et al., 1973a; Grimble \& McIlmurray, 1973; Esquenazi \& Streitfeld, 1973; Rosenthal \& Sandstrom, 1978; Wyle et al., 1977). Nevertheless, post-infection immunity does not appear to confer protection against gonorrhoea, and repeated infections are not uncommon. On occasions, reinfection has been shown to occur in patients with detectable levels of antigonococcal antibodies (Brooks \& Ingwer, 1979) and in patients with a specific blastogenic response (Grimble \& Mcllmurray, 1973). The apparent lack of protective effect of the naturally acquired immune response to the gonococcus may be taken to indicate that the gonococcal antigens are non-immunogenic, or that the antibody and cell-mediated immune responses detected are directed to antigens of little relevance in immunity.

Gonococcal antigens show variations among strains and between variants of strains (Johnston et al., 1976; Heckels, 1979, 1984; Buchanan, 1973; Lambden et al., 1981; Diaz \& Heckels, 1982; Apicella \& Gagliardi, 1979; Mandrell et al., 1986; Demarco de Hormaeche et al., 1983). An antibody response mounted against particular strain variants might have no effect on another variant or on different strains. In addition, many of the above-mentioned studies on the immune response in gonococcal infections have been made using as antigens whole-cell

Abbreviations: GIS, gonococcal infection sera; MAb, monoclonal antibody; NHP, normal human serum pool; NHS, normal human sera. 
preparations or extracts of laboratory-adapted strains of gonococci. Gonococcal antigens vary during growth in vitro, and some of the antibody detected with use of laboratory-adapted organisms may have no specificity to the relevant surface antigen determinants.

We have described in vivo-in vitro variation of gonococcal LPS antigens, using variants of strain gc40 selected by growth in vivo in subcutaneous chambers (vivo variant) or on artificial media (vitro variant). We originally designated the LPS of the vivo variant ' $C$ LPS', because it showed large amounts of an antigenic determinant which might be involved in the capsulated appearance of these organisms, and to differentiate it from that of the vitro variant (Demarco de Hormaeche et al., 1978, 1983). We have lately defined, using MAb CC1, an antigenic site which determines the previously reported differences between the vivo and vitro variant LPSs (Demarco de Hormaeche et al., 1986). As we have found the determinant in all recent isolates studied, we have now reverted to the traditional denomination of LPS, and refer to the antigenic site defined by $\mathrm{MAb} \mathrm{CCl}$ as epitope $\mathrm{C}$.

The current study was carried out to determine whether normal individuals have a background response to epitope $\mathrm{C}$ and to find out whether this epitope is antigenic during infection. Sera from normal individuals and from patients with gonorrhoea were compared in their reactivity with extracts from the vivo and vitro variants in ELISA and immunoblots. The expression of epitope $\mathrm{C}$ during infection and its antigenicity in humans were established by ELISA inhibition using MAb CCl and by differential inhibition with vivo and vitro antigen extracts.

\section{METHODS}

Bacteria. Two variants of Neisseria gonorrhoeae strain gc40 were used as antigen sources, one obtained by repeated subculture on artificial medium (vitro variant), and the other selected by growth in vivo in guinea-pig subcutaneous chambers (vivo variant); these have been described (Demarco de Hormaeche et al., 1978, 1983). The vivo variant appears capsulated, infects mouse subcutaneous chambers and resists killing by normal human serum. The vitro variant does not infect chambers, does not appear capsulated and is serum sensitive. Suspensions of organisms were frozen in aliquots and stored in liquid nitrogen; for use, vials were thawed at room temperature and cultured on plates of GcIv medium [GC base (Difco) with $1 \%(\mathrm{w} / \mathrm{v})$ Isovitalex (Becton Dickinson)] as described by Demarco de Hormaeche et al. (1986). The vivo variant was always used at the third subculture from guinea-pig chambers.

Antigens. Hot phenol/water LPS extracts were made from the vivo and vitro variants of strain gc40 using a variation of the method of Perry et al. (1978) as previously described (Demarco de Hormaeche et al., 1986). Saline extracts were made as previously described (Demarco de Hormaeche et al., 1986) from gonococci grown in the same conditions and suspended in saline to the same concentration measured as $\mathrm{OD}_{620}$.

Sera. A normal human serum pool (NHP) was made by mixing equal volumes of serum from five normal males with no history of gonococcal infection. The NHP was used as a normal standard. Serum samples from 217 normal individuals (NHS) were kindly provided by the Department of Clinical Biochemistry, New Addenbrooke's Hospital, Cambridge, UK. Sera from patients with gonococcal infection (GIS) were obtained from different areas : 17 from Cambridge, UK (from Dr M. J. Thornley, New Addenbrooke's Hospital), 28 from Liverpool, UK (from Professor K. McCarthy, Royal Liverpool Hospital), and 6 from Finland (from Dr H. Saxen, National Public Health Institute, Helsinki, Finland). All sera were stored at $-20^{\circ} \mathrm{C}$.

Monoclonal antibodies. Mouse MAb CC1, an $\operatorname{IgG} 3$ with specificity to the epitope $\mathrm{C}$, has been described (Demarco de Hormaeche et al., 1986). MAb C1C9, a murine IgG3 specific for a polysaccharide antigen of Schistosoma mansoni, was a gift from Dr D. W. Dunne (Department of Pathology, Cambridge, UK).

Antiglobulins. Horseradish-peroxidase-labelled goat anti-human immunoglobulin antisera (anti whole $\mathrm{Ig}, \mathrm{IgG}$, IgM, or IgA ; Nordic Immunological Laboratories) of similar enzyme activity were checked for specificity in our laboratory.

SDS-PAGE and Western blotting of saline extracts of gc40. SDS-PAGE, on $8-20 \%(\mathrm{w} / \mathrm{v})$ gradient gels, and transfer to nitrocellulose sheets, were done as previously described (Demarco de Hormaeche et al., 1986). Several gels were electrophoresed and blotted simultaneously. After transfer, the nitrocellulose sheets were fixed with glutaraldehyde in phosphate-buffered saline (PBS; containing, per litre, $8 \mathrm{~g} \mathrm{NaCl}, 0.2 \mathrm{~g} \mathrm{KCl}, 1 \cdot 15 \mathrm{~g} \mathrm{Na}_{2} \mathrm{HPO}_{4}$, $0.2 \mathrm{~g} \mathrm{KH}_{2} \mathrm{PO}_{4} ; \mathrm{pH} \mathrm{7.2)}$ for $15 \mathrm{~min}$, rinsed in $0.01 \mathrm{M}$-Tris buffer $\mathrm{pH} 7.4$ and cut into strips. The strips were numbered, dried, stored at room temperature and used for the testing of human sera as required. Before use, the strips were incubated in a blocking solution of $3 \%(\mathrm{w} / \mathrm{v})$ bovine serum albumin (BSA; Sigma) in $0.01 \mathrm{M}$-Tris buffer pH 7.4 with $0.15 \mathrm{M}-\mathrm{NaCl}$. This buffer with the addition of $0.05 \%(\mathrm{v} / \mathrm{v})$ Tween 20 was used for further washing and also as a diluent. The strips containing the separated antigens of the saline extract were incubated with human sera 
for $2 \mathrm{~h}$ at room temperature, washed and incubated for $1 \mathrm{~h}$ with a peroxidase-labelled goat anti-human total Ig or goat anti-human IgG, IgM or IgA. After washing, the strips were incubated in the substrate solution for $20 \mathrm{~min}$ and finally rinsed in distilled water. All steps were carried out at room temperature on a rocking platform.

ELISA. Water-phase LPS extracts, obtained by the hot phenol/water method from the vivo and vitro variants, were used as antigens in ELISA. Solutions of each extract $\left(1 \mathrm{mg} \mathrm{dry} \mathrm{weight} \mathrm{ml}^{-1}\right)$ were made in distilled water and treated with sodium deoxycholate (DOC, final concentration $0.25 \%$ ) for $15 \mathrm{~min}$ at $56^{\circ} \mathrm{C}$. The DOC-treated extracts were used to coat wells of microtitre plates (Nunc Immunoplates; Gibco) at $4 \mu \mathrm{g} \mathrm{ml}^{-1}$ in a pH 8 glycine buffer (10 mM-glycine, $20 \mathrm{~mm}-\mathrm{NaCl}, 0.2 \mathrm{~mm}$-EDTA, $10 \mathrm{~mm}-\mathrm{NaF}$ with $0.1 \%$ DOC; Reggiardo et al., 1980) in volumes of $50 \mu \mathrm{l}$ per well. Coating was carried out for $4-5 \mathrm{~h}$ at $37^{\circ} \mathrm{C}$ followed by an overnight incubation at 4$10^{\circ} \mathrm{C}$. After coating, the wells were washed four times for 3 min each with PBS pH $7 \cdot 4$ containing $0.05 \%$ Tween 20 (PBS-T). This washing procedure was repeated after each incubation throughout the assay. For testing, the human sera were diluted in PBS-T with $1 \%$ BSA (PBS-T-BSA), dispensed in triplicate $50 \mu$ l volumes into the coated wells and incubated for $2 \mathrm{~h}$ at $37^{\circ} \mathrm{C}$ in a moist box. After washing and the addition of $50 \mu \mathrm{l}$ of a peroxidase-labelled goat anti-human Ig diluted $1 / 2000$ in PBS-T-BSA, the plates were incubated for $1 \mathrm{~h}$ as above. After further washings, a $1 \%(\mathrm{w} / \mathrm{v})$ solution of $o$-phenylenediamine in $0.1 \mathrm{M}$-citrate/phosphate buffer pH 5 containing $0.4 \mu 130 \%(\mathrm{w} / \mathrm{v})$ $\mathrm{H}_{2} \mathrm{O}_{2} \mathrm{ml}^{-1}$ was added and the reaction was stopped after $10 \mathrm{~min}$ by adding $15 \mu \mathrm{l} 3 \mathrm{M}-\mathrm{H}_{2} \mathrm{SO}_{4}$ to each well. All absorbance readings were taken at $490 \mathrm{~nm}$ with a Minireader II (Dynatech). The NHP was always included in the assays at the same dilution as used for the test sera. Wells with buffer and no serum were included as blanks. Results were estimated as the ratio $\left(A_{490}\right.$ with test serum $) /\left(A_{490}\right.$ with NHP), at the corresponding dilutions.

ELISA inhibition. Inhibition of the binding of human sera to vivo variant LPS extract was performed using antigen extracts as inhibitor, or by competition with MAb CC1.

(i) Inhibition with gonococcal antigens. The vivo variant LPS extract containing epitope $\mathrm{C}$, or the vitro variant LPS extract with no detectable C epitope (Demarco de Hormaeche et al., 1986), was used as inhibitor for the binding of human antibodies to vivo variant LPS extract in ELISA. Dilutions of sera $(1 / 50)$ in PBS-T-BSA were incubated for $30 \mathrm{~min}$ at $37^{\circ} \mathrm{C}$ with equal volumes of vivo or vitro variant extracts at $5 \mu \mathrm{g} \mathrm{ml}^{-1}$ in buffer, or with buffer alone. Equal volumes of each mixture were then transferred into triplicate wells of a microtitre plate coated with vivo variant LPS at $5 \mu \mathrm{g} \mathrm{ml}^{-1}$ as described above. The plates were incubated for $2 \mathrm{~h}$ at $37^{\circ} \mathrm{C}$, washed, and incubated for $1 \mathrm{~h}$ with the peroxidase-labelled goat anti-human Ig serum diluted 1/2000 in PBS-T-BSA. The plates were then washed and incubated with the substrate solution as described above for ELISA. Results were expressed as the percentage inhibition, calculated as:

$$
\text { [ } \left.\left(A_{490} \text { with serum in buffer }\right)-\left(A_{490} \text { with serum plus inhibitor }\right) /\left(A_{490} \text { with serum in buffer }\right)\right] \times 100
$$

(ii) Inhibition with monoclonal antibodies. Human sera (1/100) and MAb CCl or MAb ClC9 (both at $200 \mu \mathrm{g} \mathrm{ml}^{-1}$ ) or buffer were dispensed in $25 \mu$ l volumes in microtitre plates coated with the vivo variant LPS extract as above. After mixing gently for $1 \mathrm{~min}$, the plates were incubated at $4-10^{\circ} \mathrm{C}$ for $20-22 \mathrm{~h}$ and the rest of the test was carried out as described above for ELISA. Each plate contained controls including NHP as a standard and also wells with no serum as blanks. The ratios $\left(A_{490}\right.$ with test serum $) /\left(A_{490}\right.$ with NHP) were calculated for each test serum diluted in buffer alone, or in buffer with MAb CC1. The percentage inhibitions were calculated as:

$$
\text { [(ratio in buffer) }-(\text { ratio in MAb) } /(\text { ratio in buffer })] \times 100
$$

Statistical analysis. The mean and standard deviation were calculated on data obtained by ELISA analysis of NHS and GIS tested against the vivo and vitro extracts in the presence or absence of inhibitors. Statistical significance was determined by Student's $t$ test.

\section{RESULTS}

\section{Western blotting}

The NHP and 51 GIS were used to probe Western blots of saline extracts made from the vivo variant of strain gc40 (Fig. 1). The NHP had antibodies reacting intensely with a band of $M_{\mathrm{r}}$ 14200. This band was also seen when using normal mouse or normal rabbit serum as probes (not shown). The NHP had antibodies reacting weakly with antigens of $M_{\mathrm{r}} 20000,40000-45000$ and 64000-68000.

All the GIS had antibodies against various antigens of the vivo variant saline extract. The antibodies found in the NHP were also present in GIS but some variations were seen. Only $71 \%$ reacted with antigens of $M_{\mathrm{r}} 14200$ (B in Fig. 1). Most of the GIS $(94 \%$ ) reacted with antigens of $M_{\mathrm{r}} 20000$, giving a much stronger reaction than that seen with the NHP (C in Fig. 1). Eighty per cent of the GIS had antibodies to antigens of low $M_{\mathrm{r}}(\mathrm{A}$ in Fig. 1) with migration characteristics similar to LPS, forming strong bands in the same position where MAb CC1 recognizes epitope 
(a)

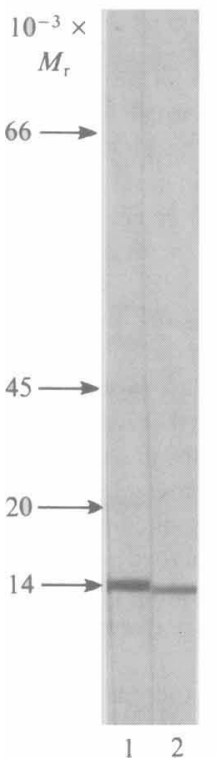

(b)

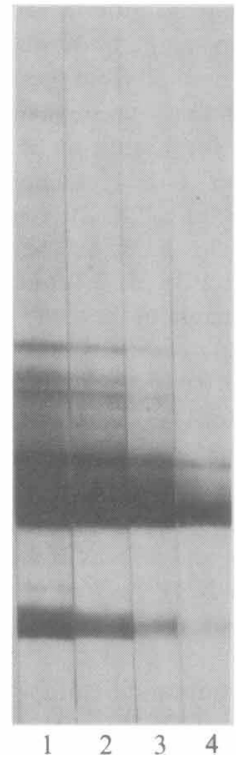

(c)

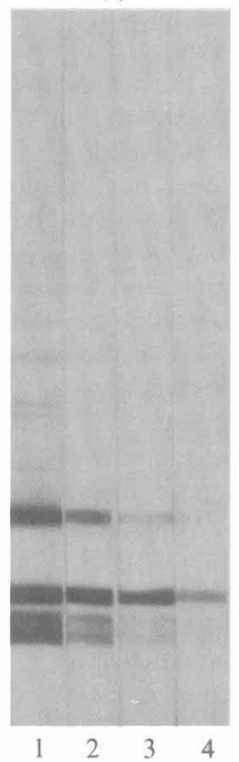

(d)

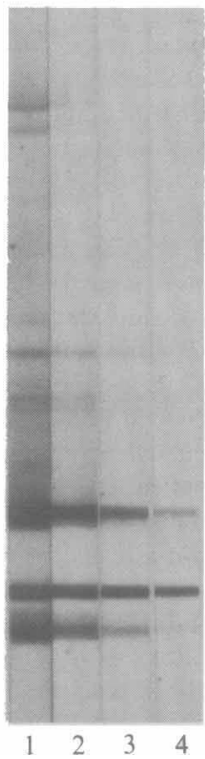

(e)

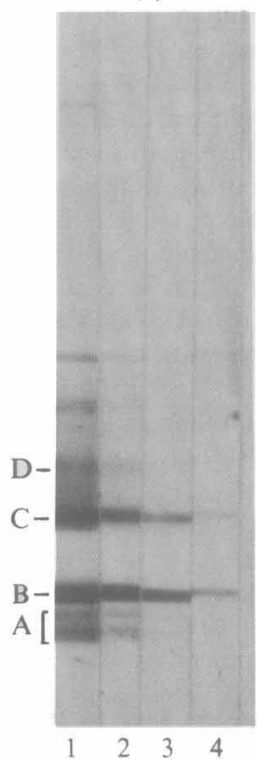

Fig. 1. Western blot of vivo variant saline extract probed with the NHP $(a)$ or with GIS from four different patients $(b-e)$. Tracks $1,2,3$ and 4 were reacted with serum diluted $1 / 50,1 / 100,1 / 200$ and $1 / 400$ respectively. Arrows on the left indicate the migration of protein standards. A, B, C and D denote bands described in the text.

C. Practically all the GIS reacted more strongly than the NHP to antigens of $M_{\mathrm{r}} 64000-68000$, and $61 \%$ had antibodies to an antigen of $M_{\mathrm{r}} 30000$ (Fig. 1, D). Bands A and D were not seen when using the NHP as a probe. The reactivity with other antigens was weak, or varied considerably from serum to serum.

Blots of vivo variant saline extracts probed with GIS were reacted with goat anti-human Ig, $\mathrm{IgG}, \mathrm{IgM}$ and $\mathrm{IgA}$. Antibodies reacting with antigens of bands $\mathrm{A}, \mathrm{B}, \mathrm{C}$ and $\mathrm{D}$ were shown by this test to be of the IgG class (Fig. 2).

Some GIS and the NHP were used to probe Western blots of saline extracts made from both the vivo and vitro variants of strain gc40 to compare the antigens of each variant and their antigenicity during infection (Fig. 3). The GIS detected important differences between the variants. Most of the GIS reacted strongly with vivo variant antigens of low $M_{\mathrm{r}}$ (bracket in Fig. 3) which represent C epitope and other LPS determinants, but only weakly with the corresponding antigens of the vitro variant, indicating antigenic changes of these components during growth in vitro and showing their antigenicity during infection. GIS also detected an antigen of $M_{\mathrm{r}} 18000$ in the vitro saline extract, not present in the vivo variant. A band of $M_{\mathrm{r}}$ approximately 20000 (which also reacted weakly with the NHP) was present in both vivo and vitro extracts but appeared to have a slightly higher $M_{\mathrm{r}}$ in the latter, suggesting that the same antigenic sites may be located in molecules of different size in each variant. Other differences between the variants were only quantitative and varied from serum to serum.

\section{ELISA and ELISA inhibition}

The GIS were tested by ELISA against the vivo variant LPS extract, which contains the C epitope. Inhibition assays were performed by incubation of the sera with LPS extracts of each variant prior to their use in ELISA. The extracts of the two variants had different inhibitory effects on the binding of GIS antibodies to antigens of the vivo LPS extract (Fig. 4). The vivo extract produced a higher inhibition (mean percentage inhibition $=44$ ) than the vitro extract 
(a)

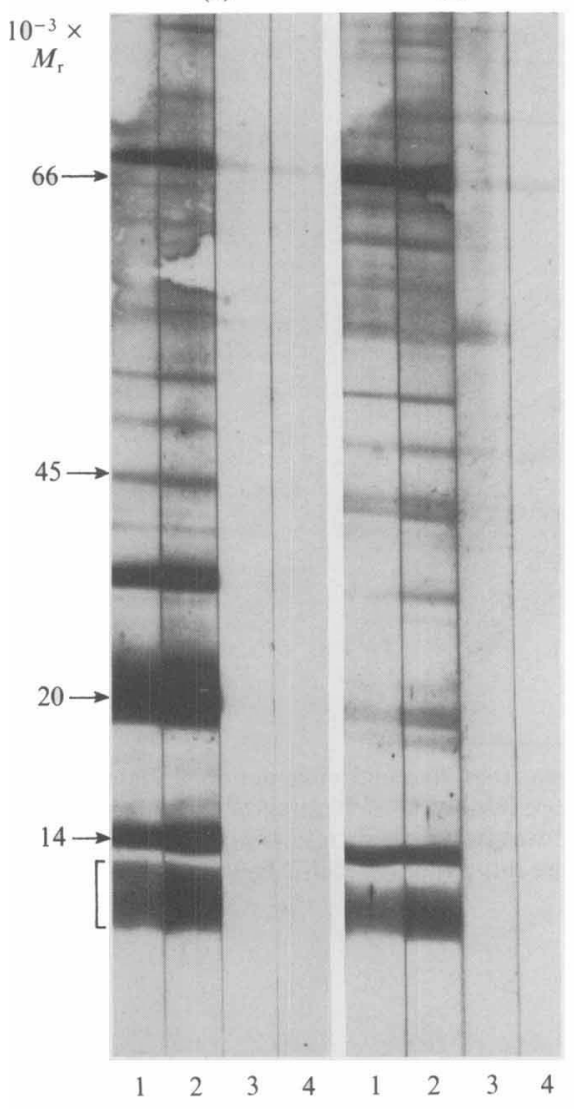

Fig. 2 (a)

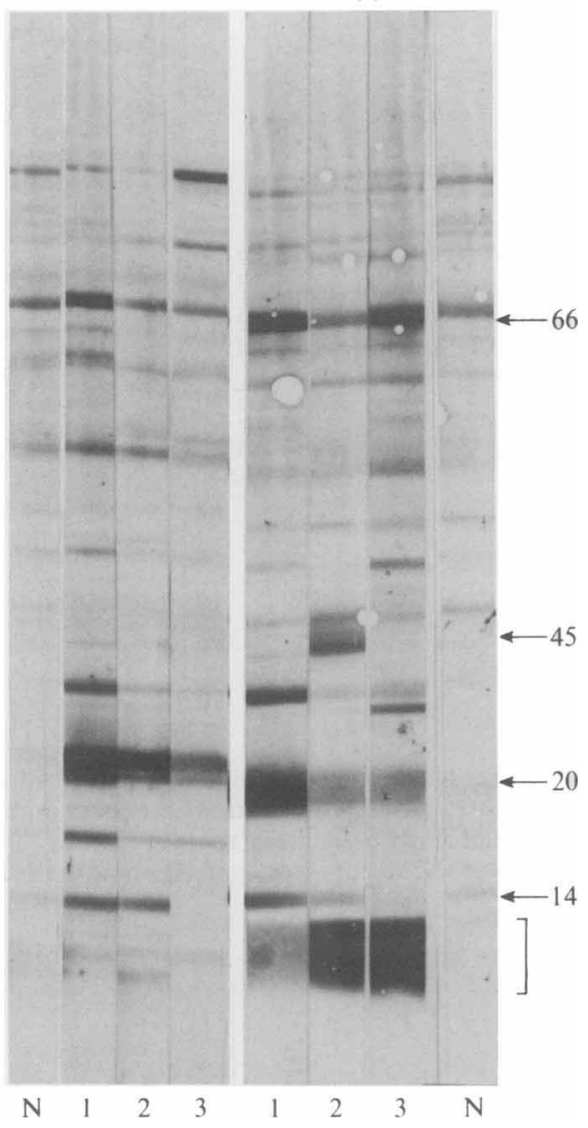

Fig. 3

Fig. 2. Western blot of the vivo variant saline extract probed with GIS from two patients $(a, b)$ developed with peroxidase-labelled goat anti-human $\operatorname{Ig}$ (track 1), IgG (track 2), IgM (track 3) and IgA (track 4). Arrows indicate the migration of protein standards. The bracket indicates migration of LPS and detection of epitope $\mathrm{C}$ in strips probed with $\mathrm{MAb} \mathrm{CCl}$.

Fig. 3. Western blots of the vitro $(a)$ and vivo $(b)$ saline extracts probed with the NHP (N) and a representative group of GIS (1,2 and 3) diluted 1/50. Arrows indicate the migration of protein standards. The bracket indicates migration of LPS and detection of epitope $\mathrm{C}$ in strips probed with $\mathrm{MAb} \mathrm{CCl}$.

(mean percentage inhibition $=13$ ), showing that the GIS antibodies reacted with epitopes poorly represented in the vitro variant.

A total of 217 NHS and 51 GIS were tested in ELISA against LPS extracts of the two variants. The NHP was tested simultaneously and the reactivity of each serum was compared with that of NHP against each antigen preparation. All the NHS had antibodies against epitopes contained in the extracts of the two variants (Fig. $5 a, b$ ). The sera varied in the levels of antibodies found but the mean NHS/NHP ratios found against the extracts of each variant were very similar. The mean NHS/NHP ratio against the vitro LPS extract was 1.03 , and that against the vivo LPS extract was 1.08 . Competition ELISA using MAb $\mathrm{CC1}$, with specificity to epitope $\mathrm{C}$, as competitor had little effect on the ratios given by NHS samples (Fig. $5 c, d$ ). The addition of $\mathrm{MAb} \mathrm{CCl}$ to the test only reduced the scatter; the mean NHS/NHP ratio (1.04) did not differ significantly from the ratios obtained in the absence of $\mathrm{MAb} \mathrm{CC}$, indicating that normal individuals do not have antibodies to the $\mathrm{C}$ epitope detectable with this system. 


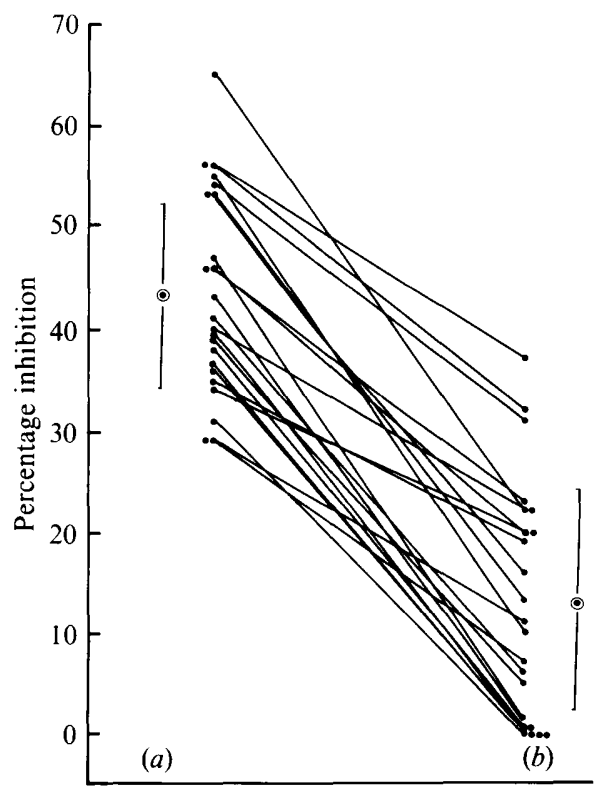

Fig. 4. Inhibition of binding of GIS in ELISA by antigen from vivo and vitro variants. Plates were coated with vivo variant LPS extract and the percentage inhibition of binding of triplicate serum samples by $5 \mu \mathrm{g}$ of the vivo $(a)$ or vitro $(b)$ variant LPS was determined; results for each serum are joined. The encircled symbols show the mean percentage inhibition by each LPS extract, \pm SD.

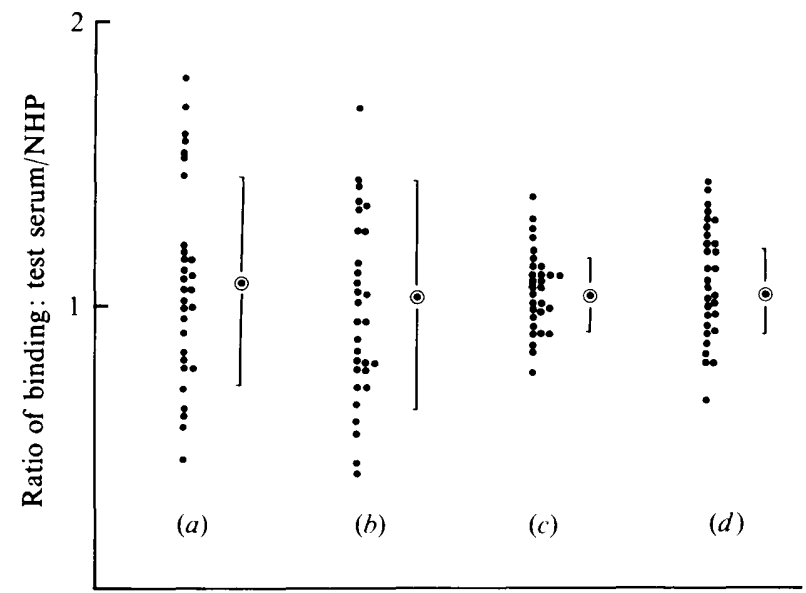

Fig. 5. Effect of MAb CCl on binding of NHS to vivo or vitro antigens. Plates were coated with the vivo $(a, c)$ or vitro $(b, d)$ variant LPS extracts, and the binding of 30 individual NHS was tested in triplicate in the absence $(a, b)$ or presence $(c, d)$ of MAb $\mathrm{CC} 1$. Each symbol represents the ratio $(\%$ inhibition of test serum $) /(\%$ inhibition of NHP). The encircled symbols show the mean \pm SD for each group.

The levels of antibodies found in the GIS varied considerably (Fig. 6). Some patients had very low levels of antibodies against both LPS extracts and some patients had high levels against both, but the difference between the mean ratios against the vivo $(1 \cdot 43)$ and vitro $(0 \cdot 86)$ extracts was significant $(P<0.001)$. The binding of antibodies to vivo LPS was reduced $(P<0.001)$ by competition with MAb CC1, to a level $(0 \cdot 84)$ similar to that obtained with the vitro extract, showing that patients with gonorrhoea have antibodies specific to epitope $\mathrm{C}$. MAb $\mathrm{ClC}$, with no specificity to the gonococcus, did not produce any inhibition. 


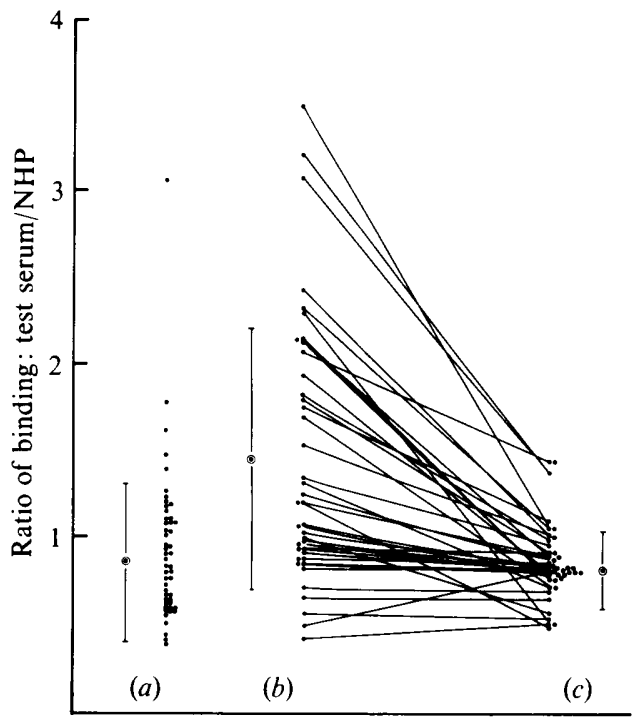

Fig. 6. Effect of MAb CCl on binding of GIS to vivo and vitro antigens. Plates were coated with the vivo or the vitro variant LPS extracts. Symbols represent the ratio (binding of test serum)/(binding of NHP) against the vitro variant LPS extract on its own (a); and against the vivo variant LPS extract in the absence $(b)$ or presence $(c)$ of $\mathrm{MAb} \mathrm{CCl}$ (results for each serum are joined). The encircled symbols show the mean \pm SD for each group.

\section{DISCUSSION}

The present results show that humans infected with gonococci develop antibodies to the C epitope of gonococcal LPS, and these antibodies were not detected in normal human sera. Normal sera did have antibodies to other LPS determinants and perhaps to other antigens present in the extracts, but not to the $C$ epitope.

Epitope $\mathrm{C}$ is the only antigenic difference we have detected between the LPS of the infective vivo variant gonococcus and the noninfective vitro derivative. We have previously reported that the $\mathrm{C}$ epitope is not present in seven different non-pathogenic neisseriae (Demarco de Hormaeche et al., 1986), which are known to share other common antigens, including LPS determinants, with virulent neisseriae.

LPS is a major target in the serum bactericidal reaction, and it has been postulated that gonococcal serum resistance may result from the absence in NHS of lytic antibodies directed against the gonococcal antigenic site for immune lysis (Schneider et al., 1982). Epitope C is a target in bactericidal reactions mediated by complement and specific antibodies (Demarco de Hormaeche et al., 1986), and may represent a locus for immune lysis during infection. We have previously shown that epitope $C$ is exposed on the surface of all cells of the vivo variant, which appear capsulated, and only in a few cells of the vitro variant, and that the vivo variant is more resistant to killing by NHS than the vitro variant (Demarco de Hormaeche et al., 1986). The resistance of the vivo variant to NHS could be explained by the absence in normal individuals of antibodies to epitope $\mathrm{C}$ demonstrated in this work. The lack of a continuous epitope $\mathrm{C}$ layer on the surface of the vitro variant may expose other LPS or protein epitopes which are targets for NHS lytic antibodies. In this way, the gonococci selected in vitro are more readily killed by NHS than those selected by growth in vivo.

The study of the immune response to the gonococcus and the development of effective vaccines against gonorrhoea require the identification of antigens common to all strains of gonococci. Most gonococcal surface antigens show extensive antigenic variation, and although some have conserved portions (Heckels, 1984), these portions are not necessarily involved in protective immunity. 
In this study we have shown that the conserved epitope $C$, involved in serum resistance and virulence, is expressed in vivo in humans and that it is antigenic. The fact that it can be lost on subculture must be taken into account when investigating the role of LPS in immunity to gonorrhoea. The efficacy of the $\mathrm{C}$ epitope as a protective immunogen and the effect of specific human antibodies on gonococci are currently under investigation.

This work was supported by a cooperative award from the Medical Research Council, UK, and Wellcome Biotech, UK.

\section{REFERENCES}

Apicella, M. A. \& Gagliardi, N. C. (1979) Antigenic heterogeneity of the nonserogroup antigen structure of Neisseria gonorrhoeae lipopolysaccharides. Infection and Immunity 26, 870-874.

Brooks, G. F. \& INGWER, I. (1979). Studies on the relationships between serum bactericidal activity and uncomplicated genital infections due to Neisseria gonorrhoeae. Journal of Infectious Diseases 158, 333-339.

Buchanan, T. M. (1973). Antigenic heterogeneity of gonococcal pili. Journal of Experimental Medicine 141, 1470-1475.

CoHen, I. R. (1967). Natural and immune human antibodies reactive with antigens of virulent Neisseria gonorrhoeae: immunoglobulins $\mathbf{G}, \mathbf{M}$, and $\mathbf{A}$. Journal of Bacteriology 94, 141-148.

Cohen, I. R., KellogG, D. S., JR \& Norins, L. C. (1969). Serum antibody response in experimental human gonorrhoea: immunoglobulins $\mathbf{G}, \mathbf{A}$ and $\mathbf{M}$. British Journal of Venereal Diseases 45, 325-327.

Demarco de Hormaeche, R., Thornley, M. J. \& Glauert, A. M. (1978). Demonstration by light and electron microscopy of capsules on gonococci recently grown in vivo. Journal of General Microbiology 106, $81-91$.

Demarco de Hormaeche, R., Thornley, M. J. \& Holmes, A. (1983). Surface antigens of gonococci: correlation with virulence and serum resistance. Journal of General Microbiology 129, 1559-1567.

Demarco de Hormaeche, R., Bundell, C., Chong, H., TAYLOR, D. W. \& WILDY, P. (1986). Definition of a virulence-related antigen of Neisseria gonorrhoeae with monoclonal antibodies and lectins. Journal of Infectious Diseases 153, 535-546.

Diaz, J. L. \& Heckels, J. E. (1982). Antigenic variation of outer membrane protein II in colonial variants of Neisseria gonorrhoeae P9. Journal of General Microbiology 128, 585-591.

Esquenazi, V. \& Streitfeld, M. M. (1973). Transformation of lymphocytes in gonorrhoea before and after therapy. Infection and Immunity 8, 503-509.

Grimble, A. S. \& McIlmurray, M. B. (1973). Cell mediated immune response in gonorrhoea. British Journal of Venereal Diseases 49, 446-449.

Heckels, J. E. (1979). The outer membrane of Neisseria gonorrhoeae: evidence that protein I is a transmembrane protein. FEMS Letters 6, 325-327.

HeCKELS, J. E. (1984). Molecular studies on the pathogenesis of gonorrhoea. Journal of Medical Microbiology 18, 293-307.

Hess, E. V., Hunter, D. K. \& ZiFf, M. (1965). Gonococcal antibodies in acute arthritis. Journal of the American Medical Association 191, 531-534.
Johnston, K. H., Holmes, K. K. \& Gotschlich, E. C. (1976). The serological classification of Neisseria gonorrhoeae. I. Isolation of the outer membrane complex responsible for serotype specificity. Journal of Experimental Medicine 143, 741-758.

Kearns, D. H., Seibert, G. B., O'Reilly, R., Lee, L. \& LogAN, L. (1973a). Paradox of the immune response to uncomplicated gonococcal urethritis. New England Journal of Medicine 289, 1170-1174.

KeaRns, D. H., O'Reilly, R. J., LeE, L. \& Welch, B. G. $(1973 b)$. Secretory IgA antibodies in the urethral exudate of men with uncomplicated urethritis due to Neisseria gonorrhoeae. Journal of Infectious Diseases 127, 99-101.

KWAPINSKI, G., KWAPINSKI, E. \& WebB, C. J. (1978). Studies on circulating gonococcal antibodies and antigens. Canadian Journal of Microbiology 24, 109 111.

Lambden, P. R., Heckels, J. E., McBride, H. \& WATT, P. J. (1981). The identification and isolation of novel pilus types produced by variants of Neisseria gonorrhoeae P9 following selection in vivo. FEMS Letters 10, 339-341.

LAMMEL, C. J., SWeEt, R. L., Rice, P. E., KNAPP, J. S., SChOolnik, G. K., HeIlboRn, D. C. \& BROOKS, G. F. (1985). Antibody-antigen specificity in the immune response to infection with Neisseria gonorrhoeae. Journal of Infectious Diseases 152, 9901001 .

Mandrell, R., Schneider, H., Apicella, M., ZolLINGER, W., RICE, P. A. \& GRIfFiss, J. M. (1986). Antigenic and physical diversity of Neisseria gonorrhoeae lipooligosaccharides. Infection and Immunity 54, 63-69.

McMillan, A., McNeillage, G. \& Young, H. (1979a). Antibodies to Neisseria gonorrhoeae: a study of the urethral exudates of 232 men. Journal of Infectious Diseases 140, 89-95.

McMillan, A., McNeillage, G., Young, H. \& BAIN, S. R. (1979b). Serum immunoglobulin response in uncomplicated gonorrhoea. British Journal of Venereal Diseases 55, 5-9.

McMillan, A., McNeillage, G., Young, H. \& Bain, S. R. $(1979 c)$. Secretory antibody response of the cervix to infection with Neisseria gonorrhoeae. British Journal of Venereal Diseases 55, 265-270.

O'Reilly, R. J., LeE, L. \& Welch, B. G. (1976). Secretory IgA antibody responses to Neisseria gonorrhoeae in the genital secretions of infected females. Journal of Infectious Diseases 133, 113-125.

Perry, M. B., Daoust, V., Johnson, K. G., Diena, B. B. \& Ashton, F. E. (1978). Gonococcal R-type lipopolysaccharides. In Immunobiology of Neisseria 
gonorrhoeae, pp. 101-107. Edited by G. F. Brooks, E. C. Gotschlich, K. K. Holmes, W. D. Sawyer \& F. E. Young. Washington, DC: American Society for Microbiology.

Reggiardo, Z., VazQuez, E. \& Schnaper, L. (1980). ELISA tests for antibodies against mycobacterial glycolipids. Journal of Immunological Methods 34, 55-60.

Rosenthal, L. \& SANDSTROM, E. (1978). Lymphocyte reactivity in patients with gonococcal urethritis. British Journal of Venereal Diseases 54, 229-234.

SCHNEIDER, H., Griffiss, J. M., Williams, G. D. \&
PIER, G. B. (1982). Immunological basis of serum resistance of Neisseria gonorrhoeae. Journal of General Microbiology 128, 13-22.

Wyle, F. A., Rowlett, C. \& Blumenthal, T. (1977). Cell mediated immune response in gonococcal infections. British Journal of Venereal Diseases 53, 353-359.

ZaK, K., Diaz, J. L., Jackson, D. \& Heckels, J. E. (1984). Antigenic variation during infection with Neisseria gonorrhoeae: detection of antibodies to surface proteins in sera of patients with gonorrhoea. Journal of Infectious Diseases 149, 166-174. 